\title{
NEOTECTÓNICA DE LAS FALLAS OCHOMOGO Y CAPELLADES Y SU RELACIÓN CON EL SISTEMA DE FALLAAGUACALIENTE, FALDA SUR MACIZO IRAZÚ-TURRIALBA, COSTA RICA
}

\author{
NEOTECTONICS OF THE OCHOMOGO AND CAPELLADES FAULTS AND ITS \\ RELATION WITH THE AGUACALIENTE FAULT SYSTEM, SOUTHERN \\ SLOPES OF THE IRAZÚ-TURRIALBA MASSIF, COSTA RICA
}

\author{
Walter Montero $^{1 *}$, Wilfredo Rojas ${ }^{1,2} \&$ Lepolt Linkimer ${ }^{1,2}$ \\ ${ }^{1}$ Centro de Investigaciones en Ciencias Geológicas, Universidad de Costa \\ Rica, Apdo. 11501-2060, Ciudad Universitaria Rodrigo Facio, Costa Rica \\ ${ }^{2}$ Escuela Centroamericana de Geología, Universidad de Costa Rica, Apdo. \\ 214-2060, Ciudad Universitaria Rodrigo Facio, Costa Rica \\ *Autor para contacto: wmontero@geologos.or.cr
}

(Recibido: 26/3/2012; aceptado: 11/6/2012)

\begin{abstract}
Geomorphic studies supplemented with geological information allow us to define the predominantly left-lateral strike-slip Capellades and Ochomogo faults. The Capellades fault connects with the Aguacaliente fault through the Cartago transpressive zone, including E-W folds and oblique (reverse-left lateral) faults. The Ochomogo fault is located between south San José and the southern slopes of the Irazú Volcano, is about $22 \mathrm{~km} \mathrm{long,} \mathrm{and} \mathrm{has} \mathrm{a}$ nearly left lateral strike slip along its E-W trend to an oblique (normal-left-lateral) slip along its ENE trending part. The interaction between the Ochomogo and Aguacaliente faults results in a transtensional regime that formed the Coris and Guarco valleys. The Capellades fault trends ENE to NE, is about $25 \mathrm{~km}$ long, and is located in the southern and southeastern slopes of the Irazú and Turrialba volcanoes. Several geomorphic features show between few meters to 0.67 $\mathrm{km}$ of left-lateral displacements along the Capellades fault trace. Based on the Middle-to-Late Pleistocene geological units exposed on the S-SE slopes of the Irazú Volcano, the fault slip rate is estimated to be between a minimum of 0.5 $\mathrm{mm} / \mathrm{yr}$ and a maximum of $1.1-3.3 \mathrm{~mm} / \mathrm{yr}$.
\end{abstract}

Keywords: Morphotectonics, neotectonics, seismicity, Irazú Volcano, Costa Rica.

RESUMEN: Estudios geomórficos complementados con información geológica permitieron definir las fallas predominantemente sinestrales Capellades y Ochomogo. Las fallas Capellades y Aguacaliente se conectan por medio de la zona de transpresión de Cartago caracterizada por fallas oblicuas inversas-sinestrales y pliegues de rumbos cercanos al E-W. La falla Ochomogo localizada entre el sur de San José y la falda sur del volcán Irazú, tiene una extensión de unos 22 $\mathrm{km}$ y varía desde un deslizamiento sinestral bastante puro en sus sectores de rumbo E-W a un desplazamiento oblicuo 
sinestral-normal en su sector de rumbo ENE. La interacción entre las fallas Ochomogo y Aguacaliente ha originado una zona de tracción que ha originado los valles de Coris y del Guarco, denominada la zona transtensiva de Coris-Guarco. La falla Capellades tiene un rumbo ENE a NE y una longitud de unos $25 \mathrm{~km}$ sobre el flanco S y SE de los volcanes Irazú y Turrialba. Indicadores geomórficos diferentes muestran desplazamientos sinestrales desde unos pocos metros hasta 0,67 km a lo largo de diversos sectores de la falla Capellades. Con base en las edades de las unidades geológicas del Pleistoceno Medio al Superior reconocidas en el flanco S-SE del volcán Irazú, se ha determinado que la tasa de deslizamiento de la falla Capellades tiene un valor mínimo de $0,5 \mathrm{~mm} /$ año y uno máximo entre 1,1 - 3,3 mm/año.

Palabras claves: Morfotectónica, neotectónica, sismicidad, volcán Irazú, Costa Rica.

\section{INTRODUCCIÓN}

En la región central de Costa Rica se presentan dos procesos geológicos activos. Por un lado, se localiza un importante vulcanismo a lo largo de la cordillera volcánica Central, que incluye los volcanes Irazú y Turrialba (Fig. 1). Además, se ha definido un sistema ancho de fallas y pliegues activos denominado Cinturón Deformado del Centro de Costa Rica (CDCCR), donde predominan las fallas dextrales con rumbos entre N-S a NW, y fallas sinestrales, de rumbos entre E-W a NE, subsidiarias de las primeras (Marshall et al., 2000; Montero, 2001).

En este estudio se realizará un breve repaso del contexto tectónico del volcán Irazú, definiéndose las fallas Ochomogo y Capellades sobre su flanco sur (Fig. 1). Asimismo, se mostrará que ambas fallas forman parte del sistema de la falla Aguacaliente. La falla Aguacaliente ha sido motivo de estudios detallados al sur y suroeste de las ciudades de San José y de Cartago (p.e. Montero et al., 1991; Woodward \& Clyde, 1993; Fernández \& Montero, 2002; Montero et al., 2005; Montero $\&$ Kruse, 2006; Montero et al., 2009). Uno de los aspectos que no había sido dilucidado en las investigaciones previas, era la continuidad al este de la falla Aguacaliente y sus características geométricas. En este estudio, mediante datos principalmente geomorfológicos, se mostrará que la falla Capellades es la continuación al este de la falla Aguacaliente, con la cual se conecta mediante el relevo transpresivo de Cartago. Asimismo, se definirá la falla Ochomogo con base en datos morfotectónicos. Igualmente se mostrará que entre la anterior falla y la Aguacaliente ha ocurrido una transtensión, que ha formado los valles de Coris y de Guarco. Más al este, la falla Ochomogo se considera alcanza la falla Capellades. Un análisis de la sismicidad histórica sugiere que la falla Capellades no ha tenido rupturas históricas, por lo cual constituye una importante amenaza sísmica para la zona central oriental de Costa Rica.

\section{CONTEXTO TECTÓNICO DEL VOLCÁN IRAZÚ}

Dentro del macizo del volcán Irazú se localizan diversas fallas sobre sus flancos norte, oeste y sur (Fig. 1). Sobre el flanco este se localizan el volcán Turrialba y algunas estructuras volcánicas y volcano-tectónicas. Una descripción detallada de las estructuras anteriores se encuentra en Montero \& Alvarado (1995), Montero (2003) y Linkimer (2003). A continuación se realiza un breve repaso de las mismas (Fig. 1). Sobre el flanco norte, destaca en el sector distal del macizo, la falla Guápiles con un movimiento predominantemente inverso (Borgia et al., 1990; Montero, 2001). Dentro del sector NNE del macizo destaca la falla Blanquito, con movimiento probablemente dextral (Montero \& Alvarado, 1995). Al norte y noroeste del cráter activo se localizan las trazas de las fallas Río Sucio Oriental, Central y Occidental (Montero \& Alvarado, 1995; Montero, 2003). Un poco al sur del cráter activo se ubica la falla Irazú, de rumbo NNE, la cual sobresale por su escarpe de falla normal facetado al oeste. Otra falla de características morfológicas y de rumbo similar existe al oriente de la anterior (Montero, 2003; 


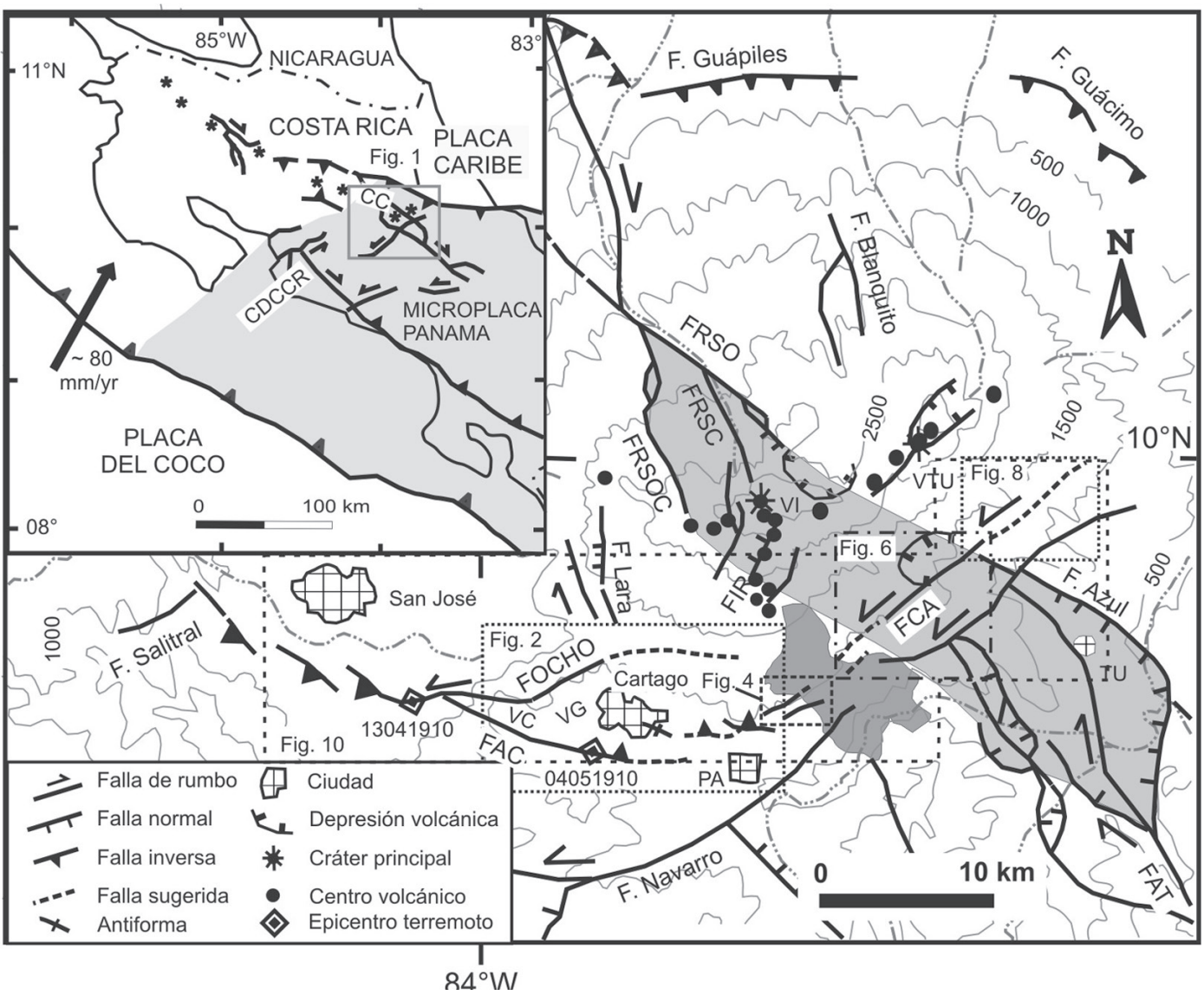

Fig. 1: Tectónica regional. Muestra las trazas de las fallas Ochomogo (FOCHO), Aguacaliente (FAC), Capellades (FCA), Río Sucio Oriental (FRSO), Río Sucio Central (FRSC), Río Sucio Occidental (FRSOC), Irazú (FIR), Atirro (FAT) y otras fallas localizadas dentro del sector central-este del Cinturón Deformado del Centro de Costa Rica (CDCCR, ver recuadro). VC y VG son respectivamente los valles de Coris y de Guarco. VI y VTU son respectivamente los volcanes Irazú y Turrialba. Se muestran los epicentros de los terremotos de 1910 (Montero, 2010). En gris claro se muestra el límite de la cuenca de tracción Turrialba-Irazú. En gris oscuro se define la colada de Cervantes de acuerdo con Alvarado et al. (2006). PA y TU son respectivamente las ciudades de Paraíso y Turrialba. Los rectángulos con diferentes simbologías muestran las áreas que cubren las figuras 2, 4, 6, 8 y 10. En el recuadro, la flecha rellena en negro muestra la velocidad relativa Coco-Caribe (DeMets et al., 2010). El rectángulo gris muestra el área que cubre la figura 1. Las estrellas ubican los volcanes cuaternarios del noroeste de Costa Rica y de la cordillera volcánica Central (CC). En gris claro se muestra la microplaca de Panamá.

Linkimer, 2003). Cerca de ambas se localizan una serie de volcanes monogenéticos (Fig. 1). Montero (2003) interpretó que un salto derecho entre las fallas dextrales Atirro y Río Sucio originó la cuenca de tracción Turrialba-Irazú (definida por gris claro en Fig. 1), estructura dentro de la cual se localizan el volcán Irazú y los focos eruptivos monogenéticos. Igualmente, este último autor interpretó que fallas como la Irazú se pueden asociar con los esfuerzos tensionales que operan dentro de esta estructura transtensiva. En la zona cuspidal del Irazú han ocurrido varios enjambres de temblores (Barquero \& Alvarado, 1989; Montero \& Alvarado, 1995; Fernández et al., 1998). Sobre el flanco occidental se ubica la falla Lara, con movimiento predominante dextral (Montero, 2001). Sobre el flanco sur a sureste se ubican las fallas sinestrales Ochomogo y Capellades, las cuales como se mostrará en las siguientes secciones forman parte del sistema de 
falla Aguacaliente. Asimismo, al sureste de la falla Capellades se localiza la falla Navarro, con un trazo subparalelo y de movimiento predominantemente sinestral (Fig. 1).

\section{LA FALLA AGUACALIENTE}

\section{Estudios previos}

La falla Aguacaliente es una de las principales fallas sinestrales reconocidas dentro de la zona central de Costa Rica (Fig. 1), asiento de la mayoría de la población e infraestructura costarricense. Con esta falla han sido asociados diversos terremotos históricos de magnitudes intermedias $\left(5,0 \leq \mathrm{M}_{\mathrm{s}} \leq 6,5\right)$, donde destacan los terremotos del 13 de abril de 1910 (00:37 y 01:05 hora local; $\mathrm{M} \sim 5,0$ y $\mathrm{M}_{\mathrm{s}} 5,8$ respectivamente; epicentro del último en Figura 1) y el desastroso terremoto del 4 de mayo de ese mismo año $\left(M_{s} 6,1\right)$, que destruyó la ciudad de Cartago y otros poblados cercanos (epicentro en Figura 1; Montero \& Miyamura, 1981; Montero et al., 2005; Montero, 2010). La falla Aguacaliente ha sido caracterizada por su movimiento predominantemente sinestral y un trazo de rumbo variable entre NW a E-W en sus diversos segmentos (Woodward \& Clyde, 1993; Fernández y Montero, 2002; Montero et al., 2005; Montero \& Kruse, 2006). Al oeste se inicia con el segmento de falla Salitral y luego continúa al este con un relevo transpresivo ubicado al oeste y sur de San José (Fig. 1). Al sureste de San José tiene un rumbo entre E-W y WNW y se subdivide en dos trazas: Aguacaliente y la que se denomina en este trabajo como falla Ochomogo (Fig. 1). Al oeste de Cartago, el sector noreste de esta última falla había sido identificado por Woodward \& Clyde (1993) como lineamientos de Ochomogo. Los mismos fueron luego redefinidos como una falla por Fernández \& Montero (2002), y posteriormente Montero \& Kruse (2006) sugieren que la misma forma parte de un sector transtensivo del sistema de falla Aguacaliente. La falla Aguacaliente, que ha sido la más estudiada, transcurre al sur de la ciudad de Cartago con un rumbo E-W. Entre el oeste de San
José y el sur de Cartago, la falla Aguacaliente ha sido definida con base en diferentes geoformas, como son el alineamiento de promontorios truncados, valles lineales, ríos y quebradas desplazadas y adaptadas, alineamiento de fuentes termales y mineralizaciones sulfurosas, escarpes y sillas de falla (Woodward \& Clyde, 1993; Fernández \& Montero, 2002; Montero et al., 2005; Montero \& Kruse, 2006). Asimismo, la falla ha sido investigada en diversas trincheras localizadas al sur y suroeste de la ciudad de Cartago (p.e., Woodward \& Clyde, 1993; Montero et al., 1991; Montero et al., 2009; Alonso-Henar, 2010). En los siguientes apartados se describirá la continuidad al este de la falla Aguacaliente y su conexión con la falla Capellades sobre la falda sur del volcán Irazú (Fig. 1). Igualmente, se redefinirá el trazo de la falla Ochomogo mediante criterios morfotectónicos y se mostrará cómo se relaciona con el sistema de falla Aguacaliente. Finalmente, se estima la tasa de deslizamiento de la falla Capellades a partir de desvíos izquierdos determinados mediante diversos indicadores geomórficos presentes en unidades geológicas del Pleistoceno Medio al Superior.

\section{La falla Ochomogo y su relación con la transtensión de Cartago}

Montero \& Kruse (2006) consideraron que la geometría de las trazas de la falla Aguacaliente en el valle de Coris y en el sector este de los cerros de La Carpintera sugerían una estructura transtensiva. En este estudio, profundizamos en esta propuesta definiendo con nuevos criterios la falla Ochomogo, la cual tendría carácter transtensivo. Esta falla de rumbo E-W a NE fue originalmente identificada en el sector este de los cerros de La Carpintera y denominado por Woodward \& Clyde (1993) como lineamientos de Ochomogo. Limita el sector sur y este de los cerros de La Carpintera con los valles de Coris y de Guarco, a lo largo de una serie de escarpes de falla facetados al este, valles lineales y desvíos de divisorias, lo cual sugiere una componente normal y sinestral en la falla (Figs. 2 y 3a). Entre los cerros de La Carpintera y la falda SW del volcán Irazú 


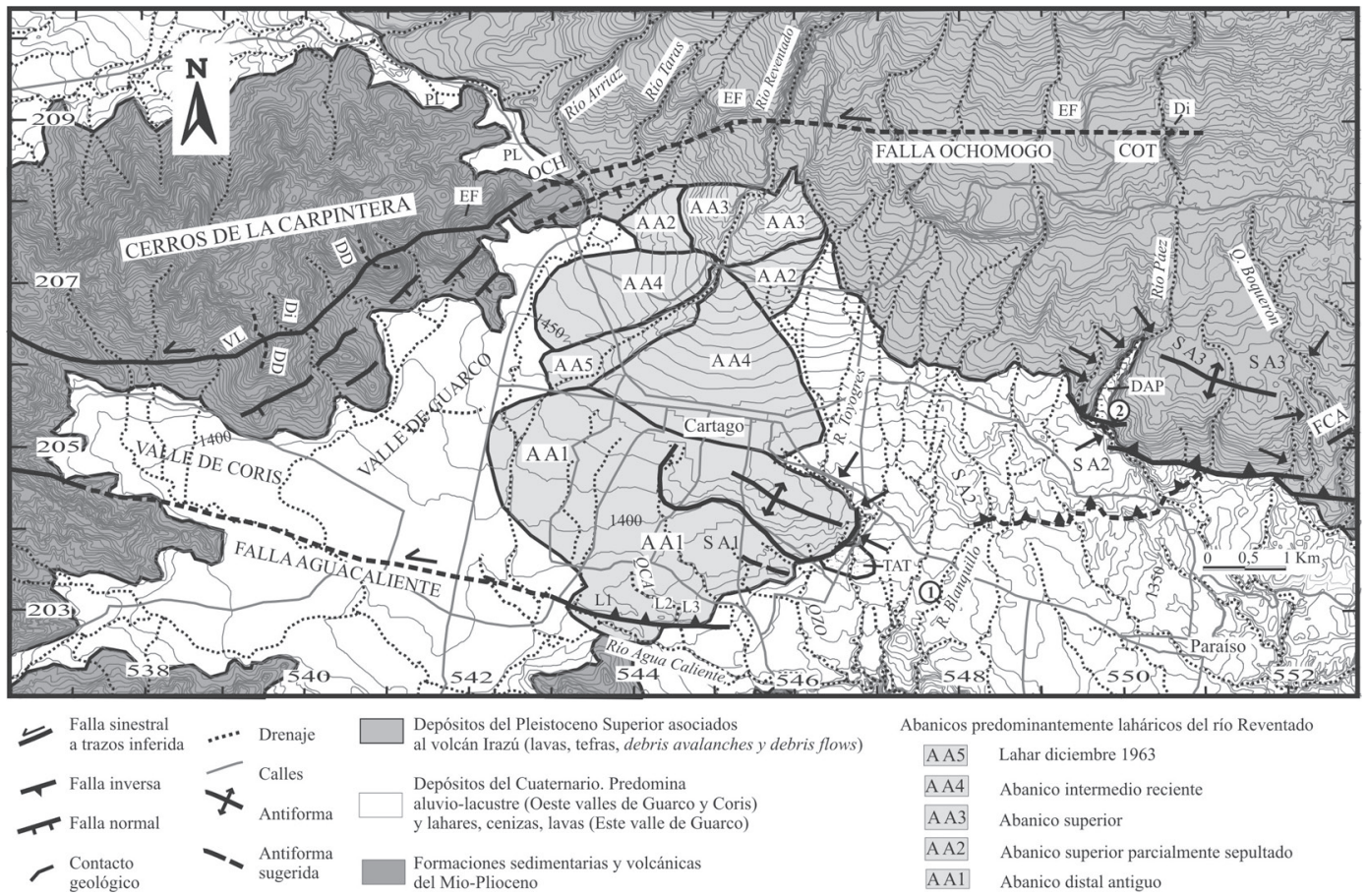

Fig. 2: Relación entre las fallas Aguacaliente y Ochomogo con la falla Capellades (FCA) dentro de los valles de Coris y de Guarco, en los cerros de La Carpintera y en la falda sur del volcán Irazú. Las fallas se reconocen por escarpes de falla (EF), desvíos izquierdos de drenajes (Di), valles lineales (VL) y divisorias desviadas (DD y líneas a trazos finas). OCH es la localidad de Ochomogo. TAT son terrazas aluviales del río Toyogres (límite definido por líneas finas). DAP son depósitos aluviales del río Páez (límite definido por líneas finas). PL son depósitos palustres. L1 a L3 corresponde con la fila de lomas entre la falla Aguacaliente y la zona transpresiva de Cartago. SA1, SA2 y SA3 son superficies aplanadas discutidas en el texto. QCA, QZO son respectivamente las quebradas Cangrejal y Zopilota. Las flechas negras definen drenajes arqueados al oeste y este posiblemente relacionados con plegamiento neotectónico. El límite sur de la antiforma al ESE de Cartago se muestra con línea negra gruesa. Los círculos con números, indican la ubicación de sitios referidos en el texto. Coordenadas en Lambert Norte. Ubicación en figura 1.

y al oeste de Ochomogo, la falla es el límite al este de una zona de divisoria de aguas continental amplia con pendiente suave al oeste, que en el pasado fue una zona de lagunar a pantanosa (PL en Fig. 2). Esta última puede explicarse por el levantamiento del bloque oeste a lo largo de la falla. Asimismo, al bajar de Ochomogo, la falla cruzaría depósitos de lahares con alteración hidrotermal. Entre los ríos Arriaz y Taras se sugieren dos trazas marcadas por escarpes y entre estas una zona de pendiente suave. Además, ambos ríos sugieren desvíos a la izquierda (Fig. 2). Hacia el este, se observan escarpes de falla facetados al sur incluyendo uno prominente en la margen derecha del río Reventado. Mediante un estudio de fotos aéreas con control parcial de campo, se ha logrado distinguir varios abanicos predominantemente laháricos asociados con el anterior río (AA1 a AA5 en Fig. 2). Una observación interesante es que los ápices de los abanicos AA2 a AA5 se ubican un poco al sur de donde la falla Ochomogo cruza el río Reventado, por lo cual podría suponerse que la localización de estos abanicos tiene control tectónico. Al cruzar el río Páez, del lado este de Cot, la falla origina un desvío izquierdo. Más al oriente, la falla pierde prominencia al cruzar la colada de Cervantes, aunque se sugiere que se puede conectar con la falla Capellades (Fig. 1, ver adelante). Lo anterior nos permite concluir que la falla Ochomogo tiene además de una componente izquierda, una componente normal en el sector de rumbo NE, lo cual concuerda con la sugerencia originalmente propuesta por Montero \& Kruse (2006). 


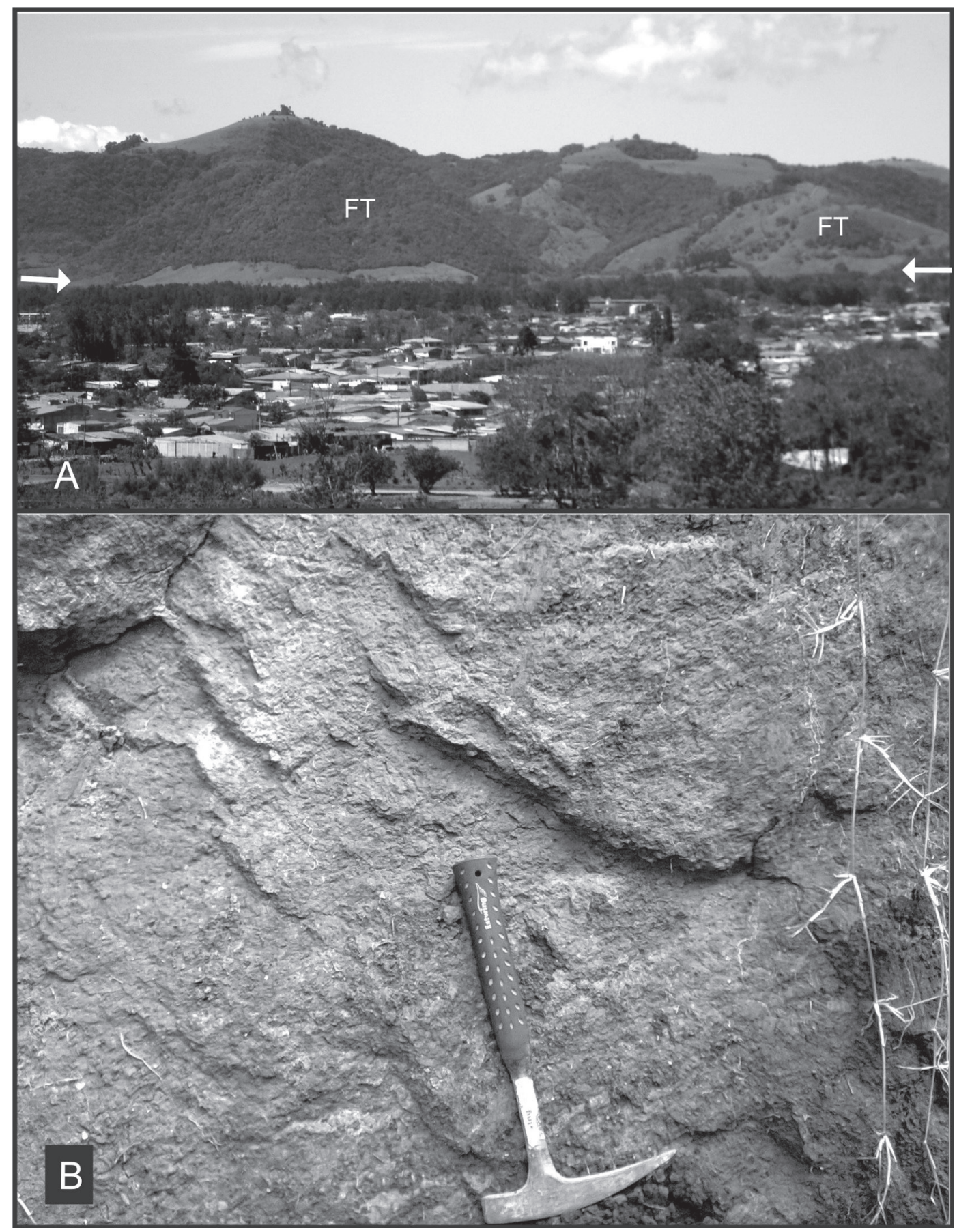

Fig. 3 A: Vista al WNW mostrando en primer plano la depresión tectónica del valle de Guarco, donde se asienta la ciudad de Cartago, limitada al fondo y al oeste por la falla Ochomogo (pie de escarpe indicado por flechas blancas), localizada sobre el sector este de los cerros de La Carpintera. La falla es evidenciada por facetas triangulares (FT), el desvío izquierdo de facetas y de divisorias, indicando sus componentes normal e izquierda. B: Fallas Riedel sintéticas con componente sinestral e inversa, que cortan un lapilli meteorizado en el sitio 2 de la figura 2. 


\section{La transpresión de Cartago y la conexión entre las fallas Aguacaliente y Capellades}

Montero \& Kruse (2006) habían planteado dos posibles alternativas para continuar la fa1la Aguacaliente al este de Cartago, una de las cuales sería de un rumbo NE y otra de un rumbo aproximado E-W. Aunque no se descarta la última hipótesis, porque por ejemplo en el sitio 1 (Fig. 2) se encontraron fallas de rumbo $\mathrm{N}^{\circ} 0^{\circ}$ $70^{\circ} \mathrm{E}, 60^{\circ}-70^{\circ} \mathrm{S}$ cortando una ignimbrita en la margen derecha del río Blanquito, nuestra nueva interpretación soporta claramente la primera hipótesis de que la falla Aguacaliente se continúa al noreste mediante un relevo transpresivo ubicado entre el sur de la ciudad de Cartago y el norte de la ciudad de Paraíso, donde conectaría con la falla Capellades (ver adelante). Las evidencias a favor de esta interpretación se discuten a continuación.

Montero \& Kruse (2006) discutieron ampliamente las evidencias morfológicas, geológicas y geofísicas, que les permitieron interpretar que la fila de colinas ubicada al sur de Cartago (L1 a L3 en Fig. 2), facetadas al sur, rumbo cercano al E-W y subyacidas por depósitos de lahares, se relacionan con una falla con componentes inversa y sinestral. Más recientemente, Montero et al. (2009) realizaron trincheras cortando las anteriores lomas. En una trinchera ubicada del lado sur de la loma L2 (Fig. 2), encontraron fallas con componente inversa inclinadas al norte y cortando depósitos aluviales recientes. En otra trinchera ubicada del lado norte de la anterior loma, encontraron bandas arcillosas de color gris en la parte superior de un lahar, que varían de inclinación de $20^{\circ}$ al $\mathrm{N}$ en el flanco norte de la loma a sub-horizontales en la parte alta de la misma, lo cual les sugirió el plegamiento de esta unidad. Depósitos aluviales represados se observan aguas arriba de las lomas L2 y L3, sobre ambas márgenes de la quebrada Cangrejal (Fig. 2). Con base en lo anterior, se interpreta que el lado sur de las lomas L1 a L3 corresponde con un frente de falla inversa inclinado al norte con componente sinestral. Es de observar que Quintanilla et al. (2008) interpretaron la presencia de la falla Aguacaliente al sur de Cartago con base en perfiles estratigráficos obtenidos de perforaciones y sugirieron una componente inversa en algunos sectores de la misma.
El frente inverso ubicado del lado sur de las lomas mencionadas anteriormente, se relevaría al noreste con una estructura antiforme que se interpreta subyacería una loma con eje de rumbo WNW, que se ubica al ESE de la ciudad de Cartago (Fig. 2). Como evidencia de la misma tenemos: 1. La existencia de esta loma morfológicamente única dentro del valle de Guarco se considera anómala tomando en cuenta que este sector del valle es subyacido por el abanico lahárico AA1 depositado por el río Reventado. Este se estima es el abanico más antiguo dado su mayor grado de disección con respecto a los abanicos AA2, AA3 y AA4. Siendo así, el patrón de curvas de nivel de esta loma difiere del esperado para un abanico lahárico. Asimismo, el patrón de las curvas de nivel de la loma sugiere una mayor inclinación en su lado sur (límite al sur anómalo es enfatizado por línea negra gruesa en la Fig. 2). 2. Curso anómalo del río Toyogres (indicado por flechas negras en Fig. 2). Del lado norte de la loma, el río Toyogres fluye al SSW hasta alcanzar el flanco NE de la loma, la cual bordea cambiando su curso primero al SE y luego al SSW y luego al salir de la loma tiene un curso al SSE. El anterior curso del río Toyogres en forma arqueada se considera anómalo, y sugiere el crecimiento de un pliegue anticlinal, cuya nariz ha venido desplazando el río hacia el este, provocando que el río tenga un curso con la forma de la nariz de la estructura antiforme. 3. Sobre el flanco SE de la loma, el río Toyogres ha depositado una serie de terrazas aluviales (indicado por TAT y mostrado con simbología de líneas finas en Fig. 2), lo cual indica un suavizamiento en el perfil de equilibrio del río al salir al sur de una estructura en proceso de levantamiento. Es de observar que, al sur de la loma anómala anterior, existen otras formas que pueden considerarse anómalas porque no siguen el patrón del abanico, como son una zona de aplanada subhorizontal (SA1 en Fig. 2) y una fila con un eje de rumbo ESE (línea a trazos largos gruesos en Fig. 2), que tiene un eje ESE de rumbo similar a la loma anómala discutida previamente. Esta zona es drenada por la quebrada Zopilota y sus afluentes.

La estructura antiforme anterior se relevaría al oriente con una zona limitada por un escarpe de rumbo E-W, facetado al sur, de unos $40 \mathrm{~m}$ de 
altura, que al norte incluye unas superficies aplanadas subhorizontales (SA2 en Fig. 2). Esta zona es disectada por los ríos Blanquillo y Páez. El primero muestra un curso anómalo similar al descrito anteriormente para el río Toyogres, lo cual podría indicar un origen similar. Por otro lado, el río Páez tiene un curso fuertemente incisado al cruzar la zona anómala. Se sugiere que esta zona anómala corresponde con una falla inversa o con un pliegue anticlinal subyacido por una falla inversa (Fig. 2).

El frente de levantamiento anterior se releva al este contra otro de rumbo cercano al E-W, pero con un escarpe de una altura mayor, entre $125-200 \mathrm{~m}$. El escarpe frontal facetado al sur se suaviza al norte con una zona subhorizontal (SA3 en Fig. 2). Del lado occidental y oriental de las anteriores lomas, los drenajes muestran un patrón arqueado al oeste y este, respectivamente (indicados por flechas negras en Fig. 2). En el sector oeste, los principales drenajes arqueados al oeste son el río Páez y una quebrada al oeste del anterior río. El río Páez muestra un desvío a la izquierda al cruzar el frente y tiene un valle ancho aguas arriba de este, incluyendo un amplio depósito aluvial sobre la margen izquierda (indicado por DAP y con simbología de líneas finas en Fig. 2), mientras que aguas abajo de la traza está encañonado. Del lado oriente, los principales drenajes convexos al este son la quebrada Boquerón y otra quebrada sin nombre al oeste de la anterior. El anterior patrón de drenaje sugiere el crecimiento lateral de una estructura antiforma subyacente, que está empujando los drenajes en las direcciones indicadas, la cual sería limitada en el piso por una falla con componente inversa y sinestral. En el sitio 2 (Fig. 2) se determinó una falla secundaria sinestral-inversa, de rumbo $\mathrm{N} 85^{\circ} \mathrm{W}, 70^{\circ} \mathrm{S}$ y estrías con un ángulo de rake de $20^{\circ}-25^{\circ}$ al $\mathrm{W}$, cortando un lapilli muy meteorizado (Fig. 3b).

Un último aspecto llamativo es el curso al suroeste del río Reventado al disectar el abanico AA4, y luego bordear del lado oeste y con un curso ligeramente arqueado el abanico AA1 y no disectando a través de la parte central de este último. Aunque la razón de lo anterior puede encontrarse en su dinámica fluvial, también pudiera ser que el curso del río Reventado en el valle de
Guarco sea controlado parcialmente por los levantamientos tectónicos que están teniendo lugar en la parte central-este de los abanicos laháricos y que se pueden estar propagando hacia el oeste de los mismos.

Como se verá más adelante, la falla Capellades tiene un rumbo NE. Por otro lado, la falla Aguacaliente al sur de Cartago tiene un rumbo cercano al E-W. Por lo tanto, los anteriores relevos con componente inversa y sinestral, que se presentan dentro del valle del Guarco y sobre la falda sur del volcán Irazú, se relacionan con el cambio de rumbo que existe entre ambas fallas, originando una zona transpresiva entre las mismas. Los escarpes facetados al sur y la antiforma con el flanco sur más empinado que el norte sugiere que el sistema de pliegues y fallas de la zona transpresiva de Cartago tiene vergencia al sur.

\section{La falla Capellades en la falda del volcán Irazú}

La falla Capellades se inicia a lo largo de dos trazas sub-paralelas, que se relevan a la derecha, al NNE de Paraíso sobre la falda sur del volcán Irazú (Fig. 1). En este sector, la falla corta formas de origen volcánico caracterizadas por colinas con divisorias bajando al SE, drenadas por quebradas y ríos con valles angostos. Al norte de la finca Pandora, la traza norte muestra desvíos izquierdos al cruzar la quebrada Parruás $(\sim 0,09$ $\mathrm{km}$, entre flechas negras en Fig. 4; cuadro 1) y en una quebrada afluente $(\sim 0,11 \mathrm{~km}$, entre flechas grises en Fig. 4; cuadro 1) y además se observaron quebradas descabezadas, desvío de divisorias, contraescarpes y cambios de pendiente (Figs. 4 y 5a). Hacia el este, la traza norte pierde expresión. La traza sur sigue valles lineales, desvíos de divisorias, hay posibles quebradas descabezadas, desvíos izquierdos en las quebradas Regado $(\sim 0,06$ $\mathrm{km}$, entre flechas grises claro en Fig. 4; cuadro 1) y Cipreses $(\sim 0,12 \mathrm{~km}$, entre flechas blancas en Fig. 4; cuadro 1) y de la loma entre estas (Fig. 4). Depósitos fluviales recientes, posiblemente represados, se observan aguas arriba de la última quebrada. Más al NE, la traza sur está cubierta por la colada Este de Cervantes, un flujo predominantemente basáltico-andesítico con estructura 


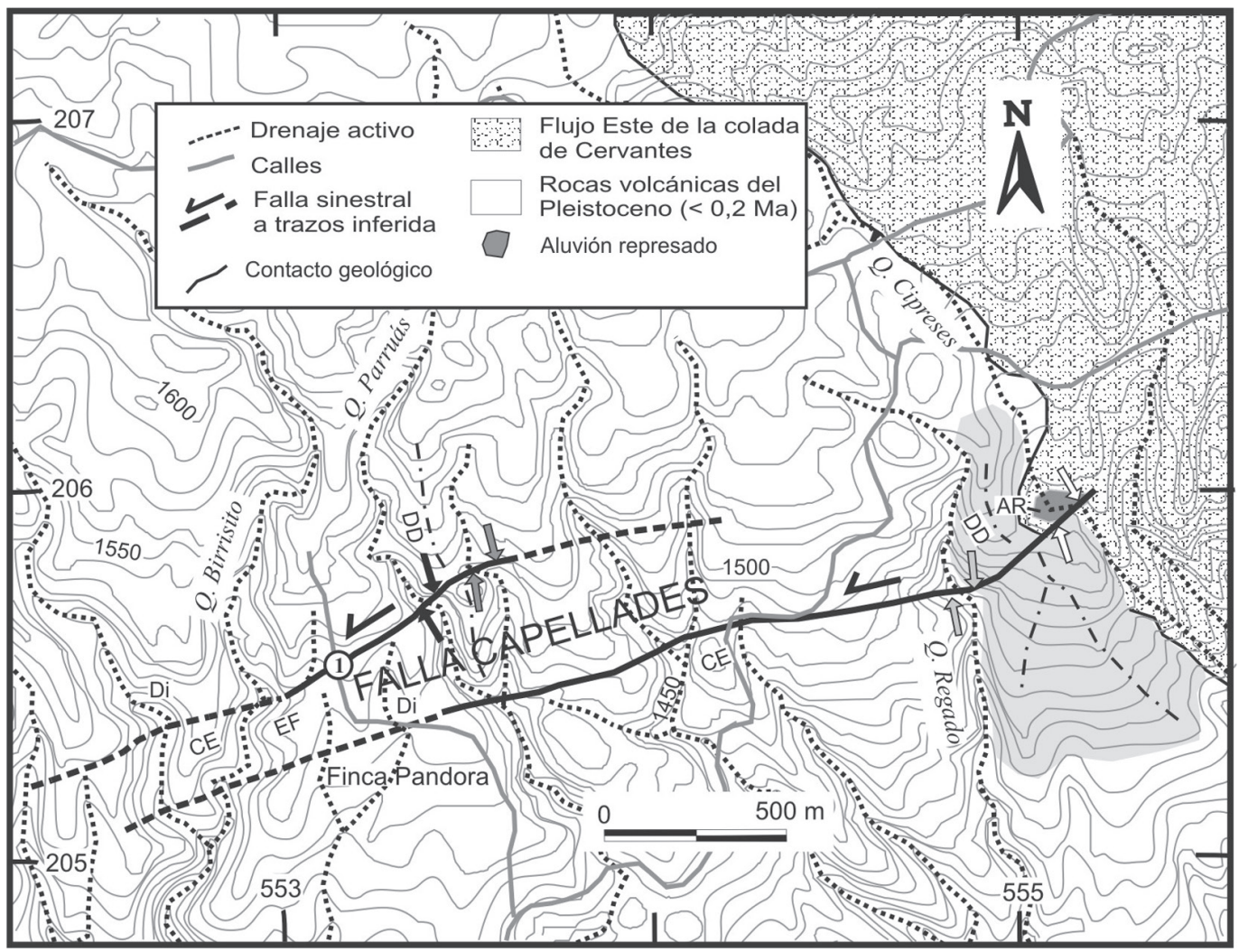

Fig. 4: Trazas sur y norte de la falla Capellades, cerca de la finca Pandora. Las trazas se reconocen por contraescarpes (CE) y escarpes de falla (EF), desvíos izquierdos de drenajes (Di), divisorias desviadas (DD y líneas a trazos y puntos) y aluvión represado (AR). Con diversas simbologías y colores entre negro y blanco se muestran los principales desvíos izquierdos referidos en el texto y en el cuadro 1. En tono gris claro se resalta la colina desviada por la traza sur. El sitio con el número 1 indica desde donde fue tomada la foto de la figura 5A. Coordenadas en Lambert Norte. Ubicación en figura 1.

en bloques relativamente sanos, de una edad de unos 17000 años (Alvarado et al., 2006) (Figs. 1 y 4). Debido a lo anterior, no fue posible definir el trazo de la falla Aguacaliente por unos $3 \mathrm{~km}$.

Del lado oriental de la colada Este de Cervantes y hasta la margen derecha del río Birrís, la falla Capellades muestra una expresión morfotectónica poco prominente. La misma se sugiere del lado sureste de Pacayas (Fig. 6). Asimismo, la traza de falla atraviesa una depresión semicircular abierta al sur, de origen desconocido, pero que puede ser relacionada con un mega-deslizamiento (¿co-sísmico?), del tipo descrito por Alvarado et al. (2004) en otras partes de Costa Rica. Entre los posibles indicadores geomórficos de la traza, en el lado oeste de la quebrada Presidio, se sugieren lomas desviadas y facetadas al norte y al sur y un posible desvío izquierdo en la anterior quebrada (sitio 1 en Fig. 6). En la margen izquierda de la quebrada Presidio, se presenta un depósito aluvial, aguas arriba del cruce de la falla. Al sur de Pacayas se observa un desvío izquierdo de $\sim 0,1 \mathrm{~km}$ en el río Pacayas (entre flechas negras en Fig. 6; cuadro 1) así como escarpes facetados al norte y al sur. Al NE, un afluente de la quebrada Patalillo, sugiere un desvío izquierdo de unos $10 \mathrm{~m}$ en el cauce y además se observa una terraza aluvial de un ancho de unos $5 \mathrm{~m}$ aguas abajo del cruce de falla (sitio 2 en Fig. 6; Fig. 5b). Sobre la margen derecha del río Birrís, una fila de rumbo SSW, que define el borde este de la depresión circular anteriormente mencionada, se corta al NNE contra la traza de falla (sitio 3 en Fig. 6). Aguas abajo del cruce de la falla, tanto el río Birrís como el curso superior de la quebrada Honda tienen un patrón sinuoso. 


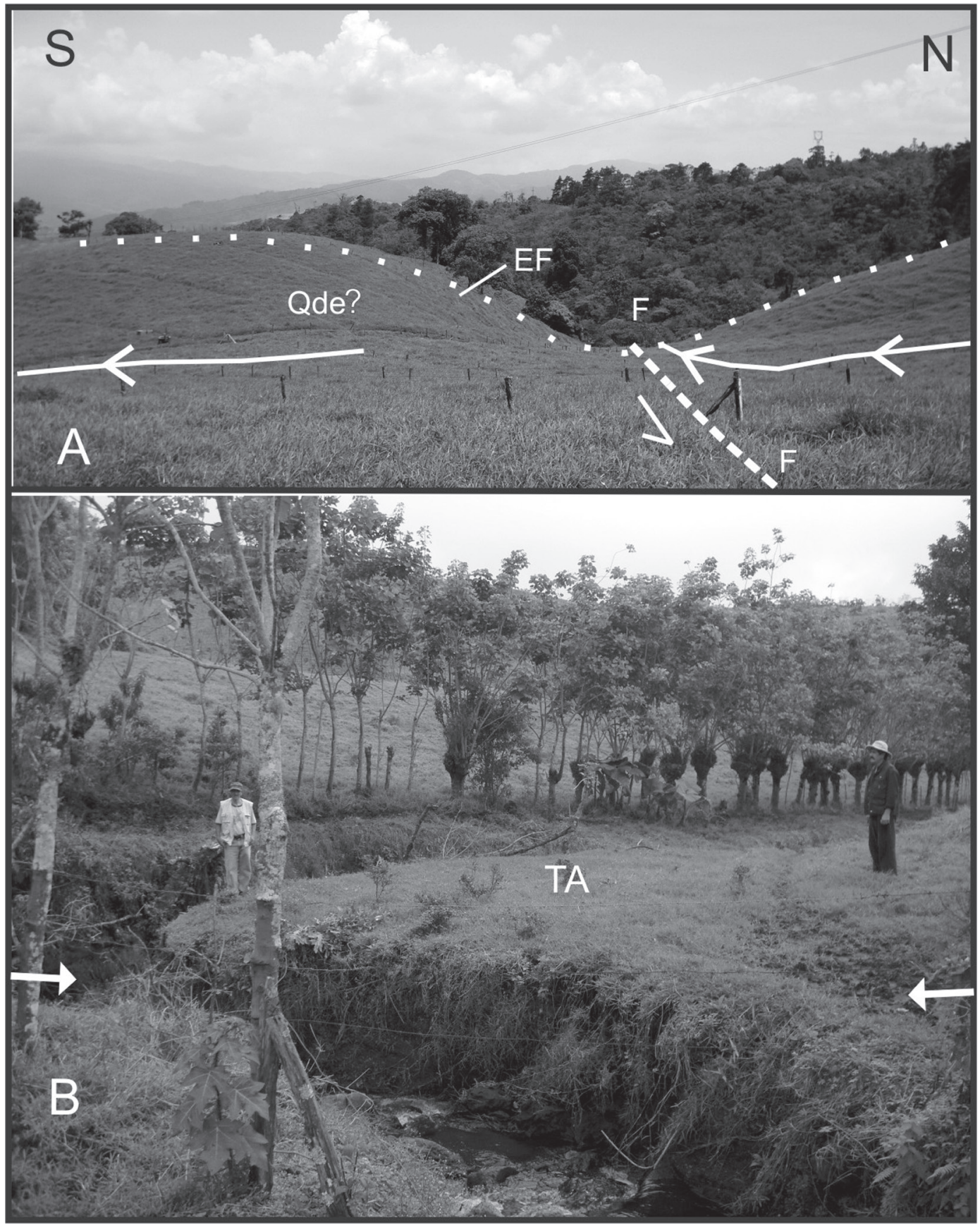

Figura 5 A: Vista al WSW del trazo norte de la falla Capellades (F y línea a trazos) desde el camino a Finca Pandora (ver Fig. 4). EF corresponde con un escarpe de falla y Qde? es una posible quebrada descabezada que del lado sur de la falla fluye al sur (a trazo continuo). La quebrada del lado norte de la falla fluye al oeste. La línea a trazos de puntos blancos marca aproximadamente la parte alta de una fila que al sur de la falla está más alta que del lado norte. La fila está sobre la margen izquierda de la quebrada Birrisito (ver Fig. 4). B: Vista al sur de terraza aluvial abandonada (TA) y posible desvío izquierdo de unos $10 \mathrm{~m}$ de un afluente a la quebrada Patalillo (sitio 2 en Fig. 6). Las flechas blancas señalan el posible trazo de falla. Foto cortesía de Nury Morales. 
Al cruzar al NE el río Birrís, la traza de falla se muestra prominente. Al sur de Capellades, la quebrada Honda se puede considerar fue el curso previo del río Birrís y es, por tanto, una quebrada descabezada (Fig. 6). Dicha quebrada tiene un valle profundo aguas abajo de la falla, mientras que aguas arriba, su cauce es superficial y con un área de cuenca muy pequeña. El desplazamiento izquierdo máximo estimado es $\sim 0,67 \mathrm{~km}$ (marcado por triángulos blanco y gris oscuro en Fig. 6; cuadro 1) y el mínimo es de $\sim 0,4 \mathrm{~km}$, considerando que el descabezamiento se relaciona con un afluente sobre la margen derecha de la quebrada Honda, que termina al NNW, en donde inicia el cañón del río Birrís (marcado entre triángulos blanco y negro en Fig. 6; cuadro 1). Linkimer (2003) propuso que la falla Pacayas, la cual consideró como un ramal del sistema de falla Navarro, originó el descabezamiento de la quebrada Honda y estimó un desplazamiento sinestral de $\sim 0,9 \mathrm{~km}$. En este estudio se propone que el descabezamiento de la quebrada Honda se relaciona con la falla Capellades. Asimismo, la magnitud del desvío izquierdo, en el río Birrís, es difícil de estimar. Un máximo sería de $\sim 0,22 \mathrm{~km}$, si se considera el tramo del río donde cambia de curso del SSE hacia el oriente, hasta el borde interno de unas terrazas abandonadas en la margen izquierda (marcado entre triángulos blanco y gris claro en Fig. 6). Los valores de desvíos anteriores son difíciles de estimar, porque ambos drenajes tienen cursos sinuosos al cruzar la falla y por la presencia de terrazas abandonadas en el río Birrís.

Al ENE del poblado de Capellades se sugiere una doble traza (sitio 4, Fig. 6); estas trazas desplazan una colina y muestran escarpes facetados y valles lineales. Más al NE, la traza sur se evidencia por escarpes facetados al norte y un desvío a la izquierda de $\sim 0,13 \mathrm{~km}$ en la quebrada Maravilla (rombos negros en Fig. 6; cuadro 1 y Fig. 7a). Del lado occidental del anfiteatro de avalancha de Coliblanco (Alvarado et al., 2004), se observan dos colinas alineadas con la traza de falla y separadas por valles lineales (sitio 6 en Fig. 6 y Fig. 7b). Dichas colinas se localizan entre dos filas de rumbo SE, donde afloran lavas andesíticas ubicadas al sur y norte de la falla. Si se asume que ambas filas eran continuas antes del inicio del desplazamiento en la falla, se tendría un desplazamiento de $\sim 0,25 \mathrm{~km}$ (flechas grises en Fig. 6; cuadro 1). Al NE del sitio anterior se localizan otras colinas de un rumbo SSE y que sugieren estar desviadas $\sim 0,30 \mathrm{~km}$ (flechas gris claro en Fig. 6; cuadro 1). Asimismo, la falla sigue un valle lineal a lo largo de un afluente del río Turrialba. Dentro de la cicatriz de avalancha, se observa un desvío izquierdo de $\sim 0,33 \mathrm{~km}$ en un tramo encañonado del río Turrialba (flechas en blanco en Fig. 6; cuadro 1). Más al NE, la traza de falla pierde prominencia.

\section{La falla Capellades en las faldas del volcán Turrialba}

Este sector de la falla fue estudiado parcialmente en el campo y los resultados se basan principalmente en interpretaciones obtenidas de las fotografías aéreas. Sobre las faldas sureste y este del volcán Turrialba la morfología es parecida a la descrita previamente para la falda sur del volcán Irazú (Figs. 1 y 8). El trazo de la falla en este sector es similar al segmento de falla Santa Cruz del sistema de falla Navarro reconocido por Linkimer (2003). La falla parece originar desvíos izquierdos al cruzar los ríos Jesús María ( 0,05 km, sitio 1 en Fig. 8 ; cuadro 1$)$, Aquiares ( $\sim, 2 \mathrm{~km}$; entre flechas negras en Fig. 8; cuadro 1), Guayabito ( $\sim, 3 \mathrm{~km}$; entre flechas grises en Fig. 8, cuadro 1), y Guayabo $(\sim 0,3 \mathrm{~km}$; entre flechas blancas en Fig. 8; cuadro $1)$, al igual que del talud NE de la fila ubicada entre la quebrada Loca y el río Guayabo $(\sim 0,3 \mathrm{~km}$; entre flechas gris claro en Fig. 8; cuadro 1) o de su divisoria $(\sim 0,2 \mathrm{~km}$; entre rombos negros en Fig. 8; cuadro 1). Una zona deprimida, que termina en forma de herradura al oeste contra la falla, y se abre en dirección SE, sugiere haber sido originada por un mega-deslizamiento, que fue movilizado a lo largo del río Guayabito (Fig. 8). Un relevo transpresivo se presenta en este sector, el cual escortado transversalmente en su parte media por un escarpe de falla facetado al este, donde el bloque oriental desciende relativamente. En el sector oriental de la zona transpresiva, se sugieren dos trazas desviando a la izquierda la margen izquierda de la quebrada Yas, antes de su confluencia con 
Cuadro 1

Desvíos izquierdos en la falla Capellades

\begin{tabular}{|c|c|c|c|c|c|}
\hline $\begin{array}{l}\text { Número } \\
\text { figura }\end{array}$ & Símbolo & $\begin{array}{c}\text { Morfología } \\
\text { desviada }\end{array}$ & $\begin{array}{l}\text { Desvío Min. } \\
(\mathrm{km})\end{array}$ & $\begin{array}{l}\text { Desvío Max. } \\
(\mathrm{km})\end{array}$ & Comentarios \\
\hline 4 & & Q. Parrúas & & 0,09 & $\begin{array}{l}\text { Distancia medida entre los rumbos de los cursos superior } \\
\text { e inferior de la quebrada proyectados a la traza de falla }\end{array}$ \\
\hline 4 & & $\begin{array}{l}\text { Afluente Q. } \\
\text { Parrúas }\end{array}$ & & 0,11 & $\begin{array}{l}\text { Distancia medida entre los rumbos de los cursos superior } \\
\text { e inferior de la quebrada proyectados a la traza de falla }\end{array}$ \\
\hline 4 & & Q. Regado & & 0,06 & $\begin{array}{l}\text { Distancia medida entre los rumbos de los cursos superior } \\
\text { e inferior de la quebrada proyectados a la traza de falla }\end{array}$ \\
\hline 4 & & Q. Cipreses & & 0,12 & $\begin{array}{l}\text { Distancia medida entre los rumbos de los cursos superior } \\
\text { e inferior de la quebrada proyectados a la traza de falla }\end{array}$ \\
\hline 6 & & R. Pacayas & & 0,10 & $\begin{array}{l}\text { Distancia medida entre los rumbos de los cursos su- } \\
\text { perior e inferior del río proyectados a la traza de falla }\end{array}$ \\
\hline 6 & & $\begin{array}{l}\text { Afluente } \\
\text { Q.Patalillo }\end{array}$ & & 0,01 & $\begin{array}{l}\text { Distancia medida entre los rumbos de los cursos superior } \\
\text { e inferior de la quebrada proyectados a la traza de falla }\end{array}$ \\
\hline 6 & & R. Birrís & & 0,22 & $\begin{array}{l}\text { Distancia medida entre los rumbos proyectados a la } \\
\text { traza de falla, del curso superior y el del borde in- } \\
\text { terno de terraza abandonada en la margen izquierda } \\
\text { del curso inferior del río Birrís }\end{array}$ \\
\hline 6 & & $\begin{array}{l}\text { Descabezamien- } \\
\text { to Q. Honda }\end{array}$ & 0,40 & & $\begin{array}{l}\text { Distancia medida entre el rumbo del curso inferior } \\
\text { de un afluente de la margen derecha de la quebrada } \\
\text { Honda y el rumbo del curso superior del río Birrís, } \\
\text { ambos proyectados a la traza de falla }\end{array}$ \\
\hline 6 & & $\begin{array}{l}\text { Descabezamien- } \\
\text { to Q. Honda }\end{array}$ & & 0,67 & $\begin{array}{l}\text { Distancia medida entre los rumbos del curso princi- } \\
\text { pal inferior de la quebrada Honda y del curso superior } \\
\text { del río Birrís, ambos proyectados a la traza de falla }\end{array}$ \\
\hline 6 & & Q. Maravilla & & 0,13 & $\begin{array}{l}\text { Distancia medida entre los rumbos de los cursos superior } \\
\text { e inferior de la quebrada proyectados a la traza de falla }\end{array}$ \\
\hline 6 & & $\begin{array}{l}\text { Fila borde oeste } \\
\text { Cicatriz colapso } \\
\text { de Coliblanco }\end{array}$ & & 0,25 & $\begin{array}{l}\text { Distancia medida entre los rumbos del borde externo } \\
\text { E de las filas ubicadas del lado norte y sur de la falla } \\
\text { proyectados a la traza de falla. Misma distancia me- } \\
\text { dida se obtiene entre los rumbos de los ejes de las } \\
\text { divisorias de las filas ubicadas del lado norte y sur de } \\
\text { la falla proyectados a la traza de falla }\end{array}$ \\
\hline 6 & & $\begin{array}{l}\text { Fila borde este } \\
\text { Cicatriz colapso } \\
\text { de Coliblanco }\end{array}$ & & 0,30 & $\begin{array}{l}\text { Distancia medida entre los rumbos proyectados a } \\
\text { la traza de falla de los ejes de las divisorias de filas } \\
\text { ubicadas al norte y sur de la falla }\end{array}$ \\
\hline 6 & & Río Turrialba & & 0,33 & $\begin{array}{l}\text { Distancia medida entre el rumbo de la margen dere- } \\
\text { cha del valle del curso superior y el rumbo de la mar- } \\
\text { gen izquierda del valle inferior proyectados ambos al } \\
\text { rumbo de la falla }\end{array}$ \\
\hline 8 & & R. Jesús María & & 0,05 & $\begin{array}{l}\text { Distancia medida entre los rumbos de los cursos su- } \\
\text { perior e inferior del río proyectados a la traza de falla }\end{array}$ \\
\hline 8 & & R. Aquiares & & 0,20 & $\begin{array}{l}\text { Distancia medida entre los rumbos de los cursos su- } \\
\text { perior e inferior del río proyectados a la traza de falla }\end{array}$ \\
\hline 8 & & R. Guayabito & & 0,30 & $\begin{array}{l}\text { Distancia medida entre los rumbos de los cursos su- } \\
\text { perior e inferior del río proyectados a la traza de falla }\end{array}$ \\
\hline
\end{tabular}


Cuadro 1

Desvíos izquierdos en la falla Capellades (continuación)

\begin{tabular}{|c|c|c|c|c|c|}
\hline $\begin{array}{l}\text { Número } \\
\text { figura }\end{array}$ & Símbolo & $\begin{array}{l}\text { Morfología } \\
\text { desviada }\end{array}$ & $\begin{array}{l}\text { Desvío Min. } \\
\quad(\mathrm{km})\end{array}$ & $\begin{array}{l}\text { Desvío Max. } \\
\quad(\mathrm{km})\end{array}$ & Comentarios \\
\hline 8 & & $\begin{array}{l}\text { Fila entre } \\
\text { Q. Loca y R. } \\
\text { Guayabo }\end{array}$ & 0,20 & & $\begin{array}{l}\text { Distancia medida entre los rumbos de los ejes de las } \\
\text { divisorias ubicadas al norte y sur de la falla, ambos } \\
\text { proyectados a la traza de falla }\end{array}$ \\
\hline 8 & & $\begin{array}{l}\text { Fila entre } \\
\text { Q. Loca y R. } \\
\text { Guayabo }\end{array}$ & & 0,30 & $\begin{array}{l}\text { Distancia medida entre los rumbos del borde E de fila } \\
\text { desviada al norte y sur de la falla, ambos proyectados } \\
\text { a la traza de falla }\end{array}$ \\
\hline 8 & & R. Guayabo & & 0,30 & $\begin{array}{l}\text { Distancia medida entre los rumbos de los cursos su- } \\
\text { perior e inferior del río proyectados a la traza de falla }\end{array}$ \\
\hline 8 & & R. Lajitas & & 0,20 & $\begin{array}{l}\text { Distancia medida entre los rumbos de los cursos su- } \\
\text { perior e inferior del río proyectados a la traza de falla }\end{array}$ \\
\hline 8 & & R. Lajas & & 0,16 & $\begin{array}{l}\text { Distancia medida entre los rumbos de los cursos su- } \\
\text { perior e inferior del río proyectados a la traza de falla }\end{array}$ \\
\hline 8 & & Q. Caño Seco & & 0,10 & $\begin{array}{l}\text { Distancia medida entre los rumbos de los cursos su- } \\
\text { perior e inferior de la quebrada proyectados a la traza } \\
\text { de falla }\end{array}$ \\
\hline
\end{tabular}

el río Guayabo (Fig. 9). Continuando al NE, la falla origina desvíos izquierdos en los ríos Lajitas ( $\sim 0,2 \mathrm{~km}$; entre triángulos negros en Fig. 8; cuadro 1), Lajas $(\sim 0,16 \mathrm{~km}$; entre triángulos grises en Fig. 8; cuadro 1) y en la quebrada Caño Seco $(\sim 0,1 \mathrm{~km}$; entre triángulos gris claro en Fig. 8; cuadro 1). Escarpes facetados al este se presentan a lo largo de la traza de falla en este último sector. Hacia el noreste la falla pierde expresión, aunque su trazo se puede continuar un poco más al NE de lo mostrado en la figura 8 (ver Fig. 1).

\section{DISCUSIÓN}

\section{Sismicidad}

En la sismicidad histórica recopilada hasta el siglo XIX no se ha interpretado ningún sismo destructivo que pueda ser relacionado con la falla Capellades (Peraldo \& Montero, 1994 y 1999). En el siglo XX, el terremoto del 4 de mayo de $1910\left(M_{\mathrm{s}} 6,1\right)$, que fue asociado con una ruptura de la falla Aguacaliente entre el valle de Coris y el sur de Cartago (epicentro en Fig. 1; Montero \& Miyamura, 1981), no parece haber disparado actividad de réplicas en la falla Capellades (Peraldo \& Montero, 2010). Lo anterior sugiere que la ruptura al este, asociada con el anterior terremoto, se paró dentro de la zona transpresiva de Cartago, la cual actuó como una barrera geométrica. Veinte y tres años después del sismo anterior, Schaufelberger \& Jiménez (1933) reportan un temblor el 22 de marzo de 1933, para el cual definieron un área mesosísmica ubicada entre Santa Cruz de Turrialba y Cartago, lugares en donde la intensidad alcanzó el grado de 5,5 en la escala Rossi - Forel (equivale a V en MM). Este sismo precedió la actividad eruptiva del volcán Irazú a partir de mayo de ese mismo año.

Con respecto a la sismicidad ocurrida en los últimos 35 años (1975-2010), los estudios han estado enfocados en la falla Aguacaliente y su continuación al oeste (p. e., Montero \& Dewey, 1982; Fernández \& Montero, 2002; Montero et al., 2005). La sismicidad con magnitud $\geq 2,5$, profundidad $\leq 15 \mathrm{~km}$, ocurrida entre 1992 y el 2010, localizada por la Red Sismológica Nacional (UCR-ICE) a lo largo del sistema de falla Aguacaliente se muestra en la figura 10. La actividad sísmica se ha localizado especialmente del lado sur de la falla Aguacaliente. Asimismo, existe una importante 


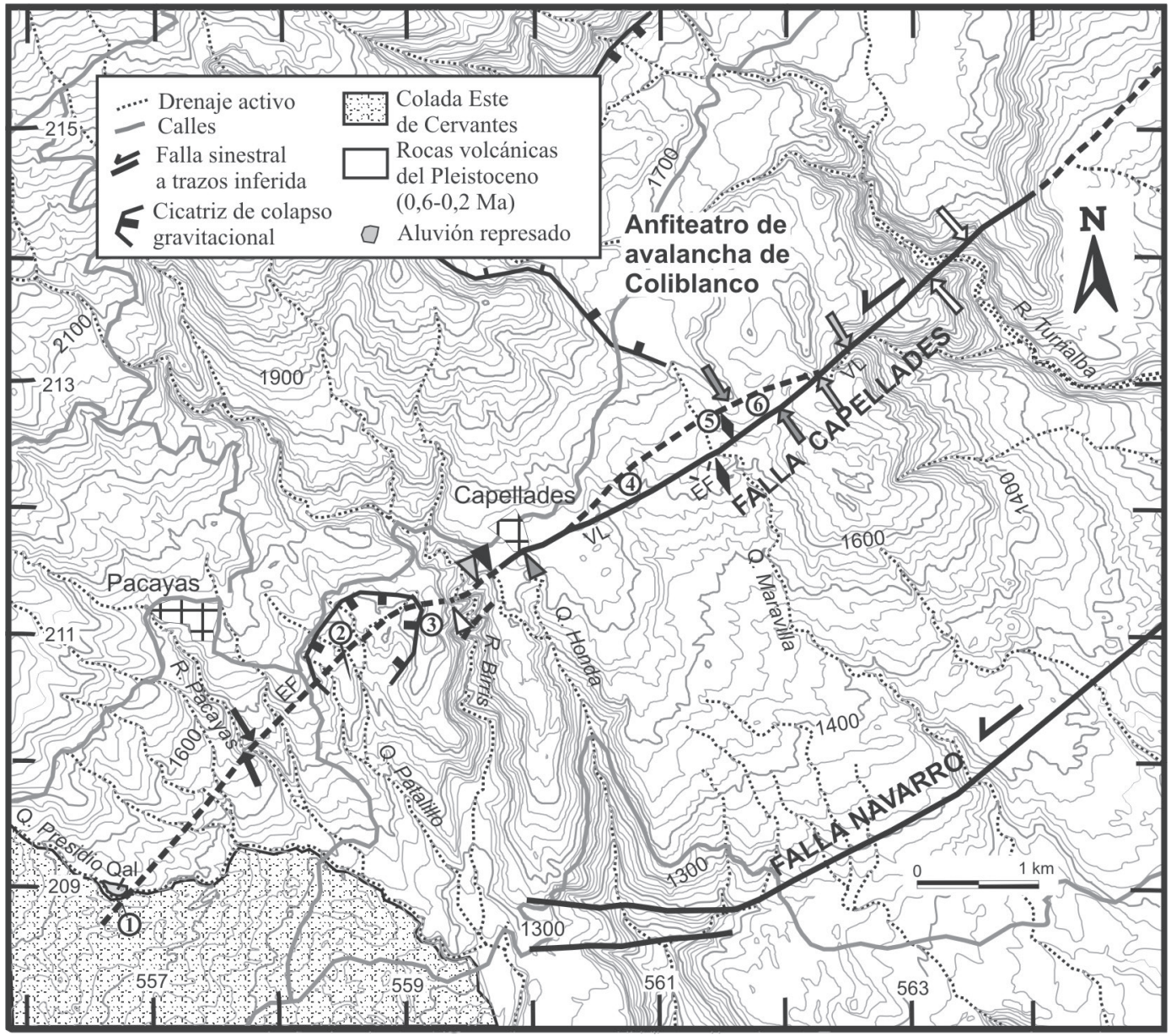

Fig. 6: Traza de la falla Capellades al sur y este de Pacayas y de Capellades. Al sur se ubica la falla Navarro. Los círculos con números indican la ubicación de sitios citados en el texto. Con diversas simbologías y colores entre negro y blanco se muestran los principales desvíos izquierdos referidos en el texto y en el cuadro 1. La falla se define por escarpes de falla (EF) y valles lineales (VL), entre otras geoformas. Coordenadas en Lambert Norte. Ubicación en figura 1.

sismicidad cerca de los relevos transpresivos localizados al oeste de la falla Aguacaliente. Con relación a los temblores ocurridos cerca de la ciudad de Cartago, destaca que varios pueden ser relacionados con la falla Ochomogo y con el sector transpresivo de Cartago.

La sismicidad que puede asociarse con la falla Capellades ocurrida durante el período indicado ha sido bastante baja (Fig. 10). Se realizaron tres mecanismos focales para tres temblores ocurridos cerca de la traza de esta falla (Fig. 10).
Los numerados 1 y 2 son consistentes con una falla noreste de movimiento izquierdo, aunque el 2 también puede ser asociado con fallamiento normal de rumbo cercano al N-S. El mecanismo focal 3 tiene los planos nodales rotados en sentido contrario a las manecillas del reloj con respecto a 1 y 2 , y su epicentro fue localizado unos $3,5 \mathrm{~km}$ al noroeste de la falla Capellades. Este mecanismo se puede relacionar con el sistema de falla dextral que ha originado el pullapart Turrialba-Irazú (Fig. 1) o con procesos magmatotectónicos asociados al macizo Irazú-Turrialba. 




Fig. 7A: Vista al sur de la falla Capellades desde el sitio 5 (Fig. 6) mostrando contraescarpes facetados al N (CE) y el desvío de la quebrada Maravilla, que al salir al sur tiene un valle encajado (QE) y aguas arriba hay un depósito aluvial represado (AR). Las flechas en blanco señalan el trazo de la falla. B: Vista al ENE de la falla desde el sitio 6 (Fig. 6) pasando por valle lineal (VL) limitado al sur por escarpe de falla facetado al norte (EF). Al fondo se muestra la divisoria de la fila desviada (FCD y línea de puntos blancos) y cortada al sur, localizada del lado norte de la falla ubicada dentro del anfiteatro de avalancha de Coliblanco (señalada por flecha gris claro en figura 6). 




Fig. 8: Traza de la falla Capellades entre el sur y el este de la localidad de Santa Cruz. Con diversas simbologías y colores entre negro y blanco se muestran los principales desvíos izquierdos referidos en el texto y en el cuadro 1. El sitio mostrado con el número 1 dentro de un círculo indica el desvío del río Jesús María. Además, se ubica la traza de la falla Navarro. El número 2 ubica el sitio desde donde fue tomada la foto de la figura 9. QCS es la quebrada Caño Seco. Coordenadas en Lambert Norte. Ubicación en figura 2.

\section{La relación tectónica entre las fallas Aguacaliente, Ochomogo y Capellades}

Entre las fallas Aguacaliente y Ochomogo se define una zona deprimida que es ocupada por los valles de Coris y del Guarco. Hasta mediados del siglo pasado, el sector oeste del valle de Coris era una zona suamposa o lagunar, mal drenada. Los bordes de ambos valles son limitados por zonas escarpadas, especialmente evidente en el lado este de los cerros de La Carpintera. La geometría de ambas fallas define en el valle de Coris el ápice de una zona de tracción que se abre al este dentro del valle de Guarco, donde se asientan las ciudades de Cartago y Paraíso, a la cual se denomina la zona transtensiva de Coris-Guarco.
Es posible que en el pasado la falla Aguacaliente se extendiera originalmente más al este de lo que se muestra en las figuras 1 y 10 como se discutió previamente. Sin embargo, en el momento presente, la falla Aguacaliente se conecta con la falla Capellades a través de la zona transpresiva de Cartago, localizada dentro de depósitos del Pleistoceno Superior al Reciente. Lo anterior parece confirmarlo la sismicidad localizada en los últimos veinte años a lo largo de la zona transpresiva de Cartago (Fig. 10) y la propuesta de que el terremoto de 1910 alcanzó a romper hasta la barrera geométrica representada por la transpresión de Cartago, la cual se explica a su vez por el cambio de rumbo E-W de la falla Aguacaliente al rumbo ENE que tiene la falla Capellades. 


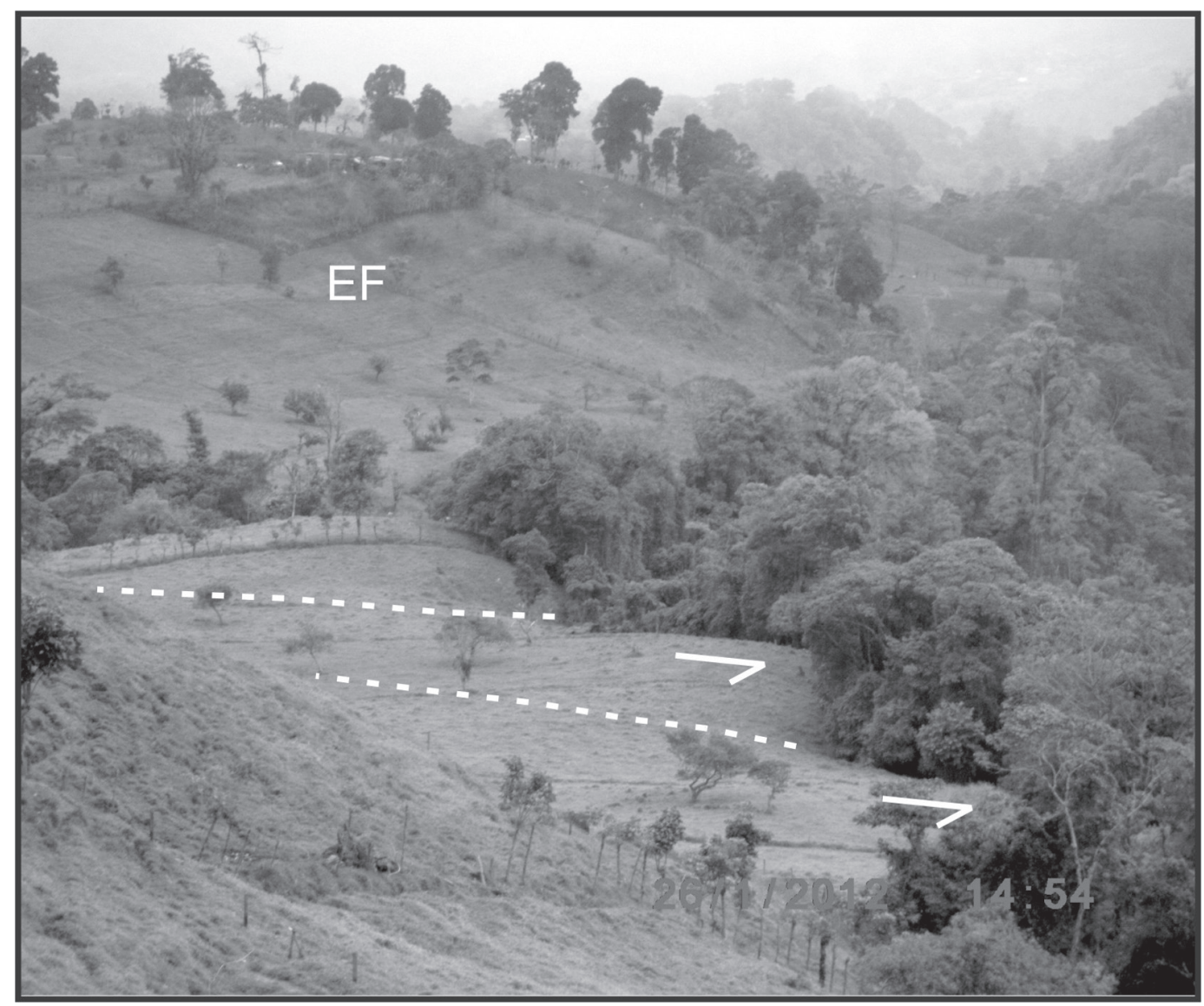

Fig. 9: Vista al SE de la margen izquierda de la zona de confluencia de la quebrada Yas con el río Guayabo mostrando dos desvíos izquierdos y un escarpe de falla (EF) asociados con diversas trazas de la falla Capellades (ver figura 8).

\section{Posible relación de la falla Capellades y las estructuras de colapso gravitacional}

Tres cicatrices de colapso gravitacional se muestran en este estudio, dos de las cuales se reportan por primera vez (Figs. 6 y 8). Las mismas se ubican cerca o a lo largo de la traza de la falla Capellades en sus sectores central y oriental. La localizada entre Pacayas y Capellades es cortada por esta falla (Fig. 6). La de Coliblanco se localiza al NW de la misma. En el caso de la del este de Santa Cruz, parte de su corona está a lo largo de la traza y luego se abre del lado SE de la falla
(Fig. 8). La ubicación de estas cicatrices de colapso con respecto a la falla Capellades, permite suponer que pueden estar relacionadas con la actividad sísmica de la misma. Los depósitos originados por el colapso gravitacional de estas estructuras son lahares y debris avalanche que se depositan en las depresiones ubicadas especialmente al sur y al este del macizo Irazú y Turrialba. Pavanelli et al. (2004) consideraron que los lahares y debris avalanche ocurridos en el flanco sur del volcán Irazú, se relacionan con la caída de ceniza y fuertes lluvias, o con un origen sísmico. Lahares o debris flow originados a partir de actividad sísmica fueron 


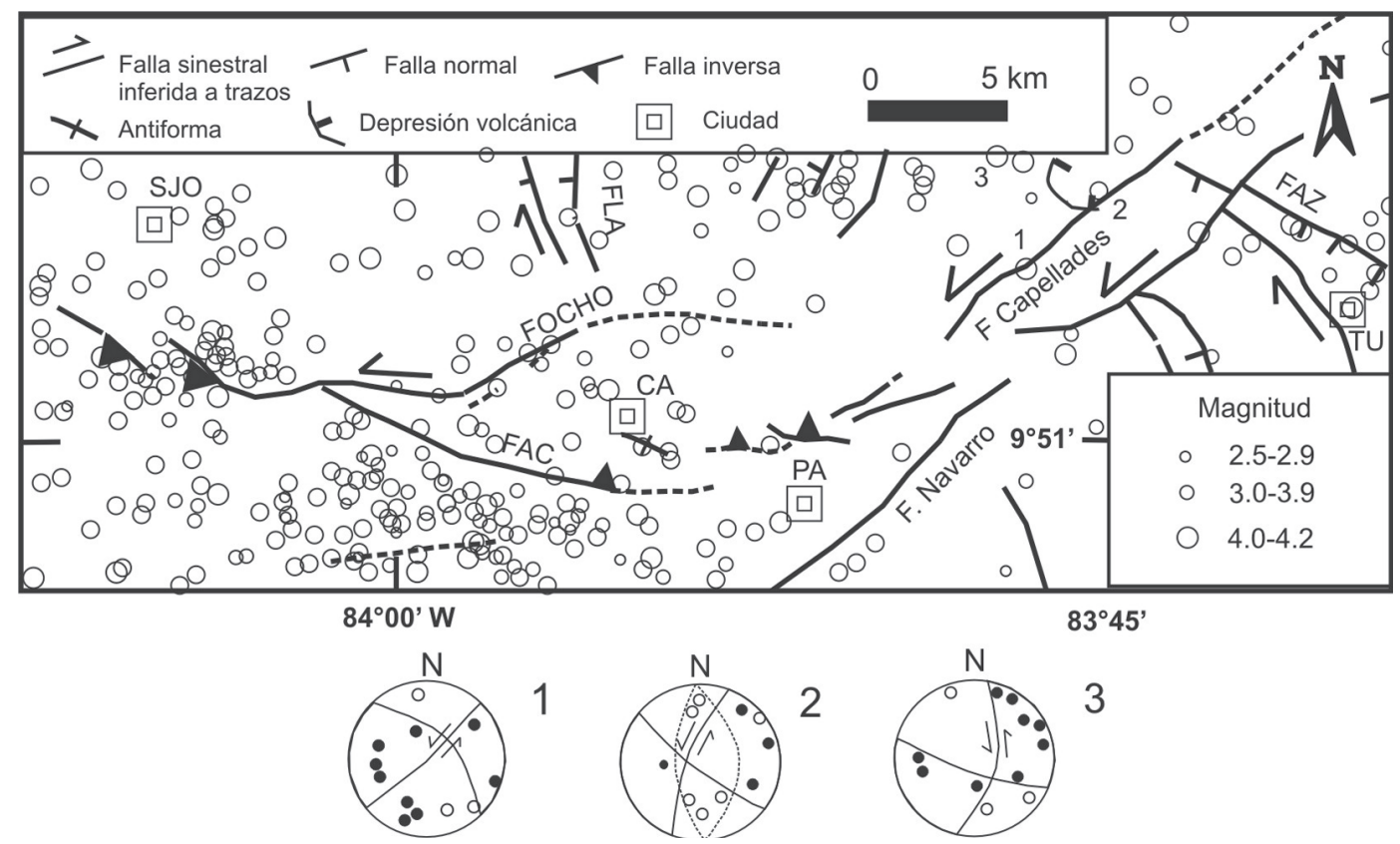

Fig. 10: Relación entre las fallas del sistema Aguacaliente y la sismicidad localizada por la RSN (UCR-ICE) de magnitud $\geq 2,5$, profundidad $\leq 15 \mathrm{~km}$, errores en la vertical y horizontal menores a $5 \mathrm{~km}$ y ocurrida entre 1992 y el 2010 . Asimismo, se muestran tres mecanismos focales realizados cerca de la falla Capellades. Las soluciones focales se proyectan en el hemisferio focal inferior, donde los círculos rellenos negros representan compresiones y los sin rellenar dilataciones. Los planos nodales que separan los datos de polarización se muestran con líneas negras, indicándose con flechas el plano nodal que indica movimiento lateral izquierdo. Además, en el mecanismo 2 se muestran los planos nodales con líneas a puntos para una solución alternativa de falla normal. FLA, FAC, FOCHO y FAZ son respectivamente las fallas Lara, Aguacaliente, Ochomogo y Azul. SJO, CA, PA y TU muestra respectivamente la ubicación de las ciudades de San José, Cartago, Paraíso y Turrialba. Ubicación en figura 1.

observados recientemente a raíz del terremoto de Cinchona $\left(\mathrm{M}_{\mathrm{w}}\right.$ 6,2) del 8 de enero del 2009 (Alvarado, 2010). Sin embargo, la relación causal entre ambos tipos de estructuras puede ser muy difícil de demostrar, dados los problemas de datación de eventos paleosísmicos que existen para las fallas activas más atrás de unos $10 \mathrm{ka}$. Asimismo, deben determinarse las edades de las estructuras de colapso y de los depósitos generados a partir del colapso. Para el debris avalanche asociado con la de Coliblanco, Alvarado et al. (2004) sugirieron una edad de $\sim 17 \mathrm{ka}$. Esta edad está más allá del límite de datación de eventos paleosísmicos normalmente reportados en la literatura.

\section{Desvíos izquierdos y tasa de deslizamiento de la falla Capellades}

En el cuadro 1 se han incorporado los desvíos de diferentes formas del terreno, especialmente de drenajes, que fueron determinados a lo largo de la falla Capellades. El cuadro lista los datos que consideramos más confiables, aunque en las figuras 4, 6 y 8 se sugieren otros. Por otro lado, dataciones recientes y rasgos geomorfológicos de rocas volcánicas en el macizo Irazú-Turrialba han logrado reconocer varias unidades dentro de este macizo (Alvarado et al., 2006; Denyer \& Alvarado, 2007), lo cual a su vez permite realizar 
estimaciones groseras de la tasa de deslizamiento en la falla Capellades. Del lado occidental de la colada Este de Cervantes, Denyer \& Alvarado (2007) sugieren que los depósitos asociados al volcán Irazú tienen edades menores a 0,2 Ma. En este sector, el desvío máximo obtenido a partir del drenaje es de $0,1 \mathrm{~km}$. Lo anterior sugiere una tasa de deslizamiento de $0,5 \mathrm{~mm} / \mathrm{año}$. Sin embargo, consideramos que esta tasa es un valor mínimo, dado que se ha estimado a partir de una edad máxima de 0,2 Ma para los depósitos y porque los drenajes desplazados sugieren ser más recientes que los depósitos. Esto último se deduce porque tienen una cuenca de alimentación reducida y están pocos entallados en sus valles. Asimismo, en el río Birrisito, que es el drenaje más importante en este tramo de la falla, no se determinó un desplazamiento confiable en la falla, posiblemente por ubicarse cerca de su terminación occidental. Al oriente de la colada Este de Cervantes, los depósitos asociados al volcán Irazú tienen edades entre 0,2 y 0,6 Ma (Fig. 6, Denyer \& Alvarado, 2007). El desvío máximo estimado es de $0,67 \mathrm{~km}$ y se asocia con el descabezamiento de la quebrada Honda en el curso superior del río Birrís, el cual se considera un río relativamente antiguo dentro del macizo y parece estar acorde con las edades estimadas para los depósitos volcánicos que corta. Con base en los anteriores valores, se estima una tasa de deslizamiento entre 1,1 a 3,3 mm/año. Estos valores pueden ser representativos de la actividad de la falla Capellades entre el Pleistoceno Medio y el Holoceno.

\section{CONCLUSIONES}

Se han identificado las fallas Capellades y Ochomogo, con una longitud de unos $25 \mathrm{~km}$ y un rumbo entre ENE a NE la primera y una longitud de unos $22 \mathrm{~km}$ y un rumbo E-W a ENE la segunda. Asimismo se ha determinado la zona transpresiva de Cartago, definida por pliegues y fallas oblicuas inversas-sinestrales. La falla Capellades se relaciona mediante un relevo transtensivo y otro transpresivo con las fallas Ochomogo y Aguacaliente, respectivamente. Por lo tanto, se puede considerar que las tres fallas forman parte del sistema de falla Aguacaliente. Con base en el descabezamiento de la quebrada Honda y el desvío máximo del río Birrís, se puede estimar un desplazamiento máximo para la falla Capellades de cerca de $0,67 \mathrm{~km}$. La tasa de deslizamiento estimada a partir de las unidades geológicas en que se ha subdividido el macizo Irazú-Turrialba, define un valor mínimo de $0,5 \mathrm{~mm} /$ año y un valor máximo entre 1,1 a 3,3 $\mathrm{mm} / \mathrm{año}$. Este último valor puede ser considerado más representativo de la actividad de la falla desde el Pleistoceno Medio. No se han identificado terremotos históricos significativos en la falla Capellades, y tomando en cuenta que en la falla Aguacaliente y en otros segmentos al occidente de la misma han ocurrido terremotos históricos destructivos (Montero et al., 2005), y que la última ruptura en la falla Aguacaliente fue a raíz del terremoto de Cartago del 4 de mayo de 1910 (M 6,1; Alonso-Henar, 2011), se puede inferir que la falla Capellades presenta una mayor amenaza sísmica en el momento presente.

\section{AGRADECIMIENTOS}

Este artículo forma parte de las actividades de los proyectos de investigación 830-A8-133 y 830B1-504 financiados ambos por la Universidad de Costa Rica y el segundo también mediante el Fondo de Incentivos del Ministerio de Ciencia y Tecnología, instituciones a quienes agradecemos su apoyo. Se agradece a Elena Badilla por proporcionar los modelos de elevación digital que sirvieron de base para dibujar varias figuras y estimar mejor los valores de desvíos descritos en el cuadro 1. Willy Salazar colaboró en la selección 
de los datos sismológicos. Nury Morales colaboró en el trabajo de campo. Se agradece a Guillermo Alvarado, Ivonne Arroyo y José Miguel Azañón por sus valiosos comentarios, los cuales permitieron mejorar este trabajo.

\section{REFERENCIAS}

ALONSO-HENAR, J., 2011: Análisis morfotectónico y paleosísmico de la falla Aguacaliente (Valle Central de Costa Rica).- 48 págs. Univ. Complutense de Madrid, Madrid [Tesis M.Sc.].

ALVARADO, G.E., 2010: Aspectos geohidrológicos y sedimentológicos de los flujos de lodo asociados al terremoto de Cinchona $\left(M_{w} 6,2\right)$ del 8 de enero del 2009, Costa Rica.- Rev. Geol. Amér. Central, 43: 67-99.

ALVARADO, G.E., CARR, M.J., TURRIN, B., SWISHER, C., SCHMINCKE, H. \& HUDNUT, K.W., 2006: Recent volcanic history of Irazú volcano, Costa Rica: Alternation and mixing of two magma batches, and pervasive mixing.- En: ROSE, W., BLUTH, G.J.S., CARR, M. J., EWERT, J., PATINO, L.C. \& VALLANCE, J. (eds): Volcanic Hazards in Central America.- Geol. Soc. of Amer. Spec. Paper, 412: 259-276.

ALVARADO, G.E., VEGA, E., CHAVES, J. \& VÁSQUEZ, M., 2004: Los grandes deslizamientos (volcánicos y no volcánicos) de tipo debris avalanche en Costa Rica.- Rev. Geol. Amér. Central, 30: 83-99.

BARQUERO, R. \& ALVARADO, G.E., 1989: Los enjambres de temblores en el arco volcánico de Costa Rica.- Bol. Observ. Vulcanol. Arenal, 2: 18-39.

BORGIA, A., BURR, J., MONTERO, W., ALVARADO, G. \& MORALES, L.D., 1990: Fault propagation folds induced by gravitational failure and slumping of the
Costa Rica Volcanic Range: Implications for large terrestrial and Martian edifices.J. Geophys. Res., 95: 14357-14382.

DENYER, P., \& ALVARADO, G.E., 2007: Mapa geológico de Costa Rica.- Escala 1:400 000, Librería Francesa, San José.

DEMETS, C., GORDON, R. \& ARGUS, D., 2010: Geologically current plate motions.Geophys. J. Intern, 181: 1-80.

FERNÁNDEZ, M. \& MONTERO, W., 2002: Fallamiento y sismicidad del área entre Cartago y San José, valle Central de Costa Rica.- Rev. Geol. Amér. Central, 26: 25-37.

FERNÁNDEZ, M., MORA, M., \& BARQUERO, R., 1998: Los procesos sísmicos en el volcán Irazú.- Rev. Geol. Amér. Central, 21: 47-59.

LINKIMER, L., 2003: Neotectónica del extremo oriental del Cinturón Deformado del Centro de Costa Rica.- 103 págs. Univ. de Costa Rica, San José [Tesis Lic.]

MARSHALL, J.S., FISHER, D.M., \& GARDNER, T.W., 2000: Central Costa Rica deformed belt: Kinematics of diffuse faulting across the western Panama block.Tectonics, 19: 468-492.

MONTERO, W., 2001: El Cinturón Deformado del Centro de Costa Rica: Frontera oeste de la microplaca de Panamá.- Rev. Geol. Amér. Central, 24: 29-56.

MONTERO, W., 2003: El sistema de falla AtirroRío Sucio y la cuenca de tracción TurrialbaIrazú: Indentación tectónica relacionada con la colisión del levantamiento del Coco.Rev. Geol. Amér. Central, 28: 5-29.

MONTERO, W., 2010: El Terremoto de Cartago del 4 de mayo de 1910: Aspectos sismológicos y neotectónicos.- En: PERALDO, G. \& ACEVEDO, B. (eds.): Efemérides de la 
destrucción de Cartago cien años después (1910-2010).- Ediciones Perro Azul, San José: $37-47$.

MONTERO, W., \& ALVARADO, G.E., 1995: El terremoto de Patillos del 30 de diciembre de $1952\left(\mathrm{M}_{\mathrm{s}}=5,9\right)$ y el contexto neotectónico de la región del volcán Irazú, Costa Rica.- Rev. Geol. Amér. Central, 18: 25-42.

MONTERO, W., BARAHONA, M., ROJAS, W. \& TAYLOR, M., 2005: Los sistemas de falla Aguacaliente y Río Azul y relevos compresivos asociados, valle Central de Costa Rica.- Rev. Geol. Amér. Central, 33: 7-27.

MONTERO, W.\&KRUSE, S., 2006: Neotectónica y geofísica de la falla Aguacaliente en los valles de Coris y del Guarco.- Rev. Geol. Amér. Central, 34-35: 43-58.

MONTERO, W. \& MIYAMURA, S., 1981: Distribución de intensidades y estimación de los parámetros focales de los terremotos de Cartago de 1910, Costa Rica, América Central.- Rev. Inst. Geogr. Nacional, JulioDiciembre: 9-34.

MONTERO, W., OBANDO, L., MORA, R., SALAZAR, L. G. \& LEANDRO G., 1991: Informe Final Proyectos Habitacionales Los Diques y Duarco-Suerre.- 72 págs. Univ. de Costa Rica, San José [Inf. interno].

MONTERO, W., OBANDO, L. \& ROJAS, W., 2009: Estudio de amenaza de ruptura de falla para el proyecto Habitacional del Comité de Vivienda de Cocorí, Aguacaliente, Cartago.- 38 págs. Univ. de Costa Rica San José [Inf. interno].
PAVANELLI, N., CAPACCIONI, B., SAROCCHI, D., CALDERONI, G., VASELLI, O., TASSI, F., \& DUARTE, E., 2004: Geology and stability of the southern flank of Irazu volcano, Costa Rica.- Acta Vulcanologica, 16: 1-7.

PERALDO, G. \& MONTERO, W., 1994: Terremotos coloniales de Costa Rica.- 162 págs. Ed. Tecnológica de Costa Rica, Cartago.

PERALDO, G., \& MONTERO, W., 1999: Sismología Histórica de América Central.347 págs. Inst. Panamer. de Geogr. e Hist. Publ. No. 513, México D.F.

PERALDO, G. \& MONTERO, W., 2010: Sismicidad anterior y posterior a los terremotos del 13 de abril y el 5 de mayo.- En PERALDO, G. \& BENJAMÍN, A. (eds.): Efemérides de la destrucción de la ciudad de Cartago. Cien años después (19102010). Ed. Perro Azul, San José: 23-35.

QUINTANILLA, E., ALVARADO, G.E., MARÍN, C. DURÁN, M., 2008: Volcanoestratigrafía de pozos como un aporte al conocimiento de la geología del cuaternario del valle de El Guarco (Cartago), Costa Rica.- Rev. Geol. Amér. Central, 38: 53-64.

SCHAUFELBER, P. \& JIMÉNEZ, E., 1933: Algunas nociones sobre terremotos y temblores en Costa Rica.- 31 págs. Apuntes de Geología 7, Publicaciones Liceo de Costa Rica, 15, Imprenta La Tribuna, San José.

WOODWARD \& CLYDE, 1993: A preliminary evaluation of earthquake and volcanic hazards significant to the major population centers of the Valle Central, Costa Rica.- 89 págs. Ret Corporation, San Francisco [Inf. interno]. 
